\title{
THE RADICAL CURE OF DIRECT INGUINAL HERNIA. ${ }^{1}$
}

\author{
BY GWILYM G. DAVIS, M.D.,
}

OF PHILADELPHIA.

THE radical cure operations for both oblique inguinal and femoral hernias are fairly well understood and satisfactory. Direct hernia is much less frequent, not so well understood and not infrequently its operative treatment is quite difficult and not always satisfactory. The direct hernias which have come under my notice have presented themselves in two forms. One form pushes its way through the conjoined tendon and comes out of the external ring. It possesses as its coverings the peritoneum, sub-peritoneal fat, transversalis fascia and thinned conjoined tendon, and intercolumnar fascia, all usually more or less matted together. The other form bulges around the outer edge of the conjoined tendon and gradually decreases in size as it extends out toward the deep epigastric artery. It is pear shaped rather than spherical in form.

In this form we might expect to see the remains of the obliterated hypogastric artery going over the sac, but I have seen no evidence of it: possibly it has been pushed to the inner side behind the edge of the rectus muscle. It is recognized that when muscular and tendinous tissues are thick and abundant the operations for the radical cure of hernia are quite satisfactory and easy of performance. It is just the opposite condition that is confronted in direct hernia. The relation and construction of the conjoined tendon should be borne in mind. This tendon which is formed by the fusing together of the aponeurotic tendons of the transversalis and internal oblique muscles at the linea semilunaris passes over the rectus muscle and is almost immediately joined by the aponeurosis of the external oblique to form the sheath of the rectus. Thus it is seen that the insertion of the conjoined tendon and sheath of the rectus

\footnotetext{
${ }^{2}$ Read before the Philadelphia Academy of Surgery, October 2, 1905.
} 
are practically the same. The sheath below the fold of Douglas is entirely in front of the muscles. Posterior to the muscle is transversalis fascia only. As the sheath descends it inserts into the crest of the pubis its spine and a short distance-about an inch-along the ileo pectineal line. The outer or lower edge of the conjoined tenclon (sheath of rectus) fuses into and blends with the transversalis fascia as it goes out to the deep epigastric artery. This being the case the conjoined tendon has no free edge unless it is made by the knife clissecting it away from the transversalis fascia beneath.

Below, lying on Poupart's ligament is the spermatic cord covered by the fibres of the cremaster. The cremaster is nothing more than the lower edge of the muscular fibres and connective tissue of the internal oblique continued down over the cord.

In performing a radical cure of oblique hernia these cremaster fibres are sometimes quite abundant and inay, as I have clone, be utilized in closing the canal, but in direct hernia they are apt to be too scanty to be of any service. In oblique hernia the gap from the deep epigastric artery to the spine of the pubes is closed by bringing down the internal oblique muscle and conjoined tendon and sewing them beneath the cord (Bassini) to Poupart's ligament; but in direct hernia these tissues are so scanty that they are insufficient for the purpose. The suggestion of Halsted to take a flap from the sheath of the rectus and turn it outward I have never tried. The usual method resorted to to reinforce this weak spot is that of Wölfer and Bloodgood of opening the sheath of the rectus and dragging its fibres outward and sewing them to Poupart's ligament. The incision for exposing the rectus is shown in Fig. 1 . The external oblique has been turned back exposing the internal oblique. The conjoined tendon is drawn up and in by a retractor introduced beneath it ont toward the muscular fibres. The incision is then made from the muscular fibres toward the spine of the pubis. This incision is practically made through the lower edge of the conjoined tendon because this latter fades away into the transversalis fascia in the direction of the deep epigastric artery. The transversalis fascia is then pushed back from the posterior surface of the rectus and the conjoined tendon (sheath of the rectus) raised up from 


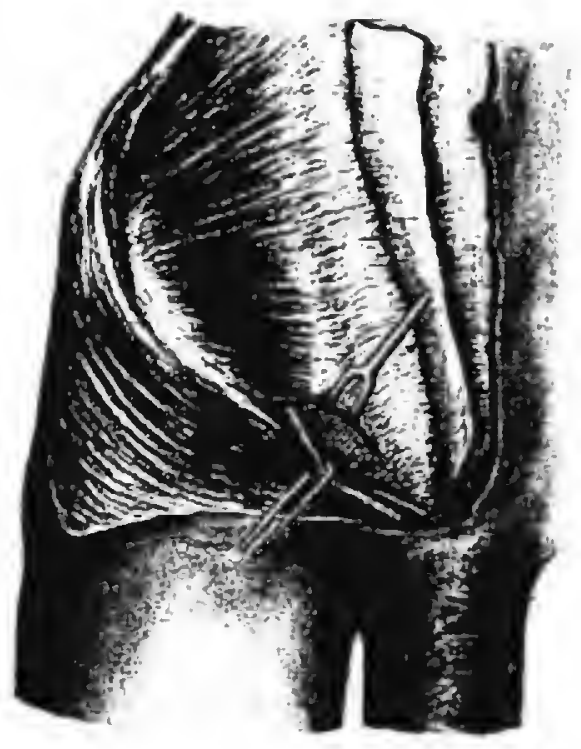

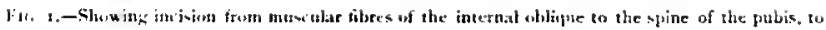
evine the elge of the rectu- muste 


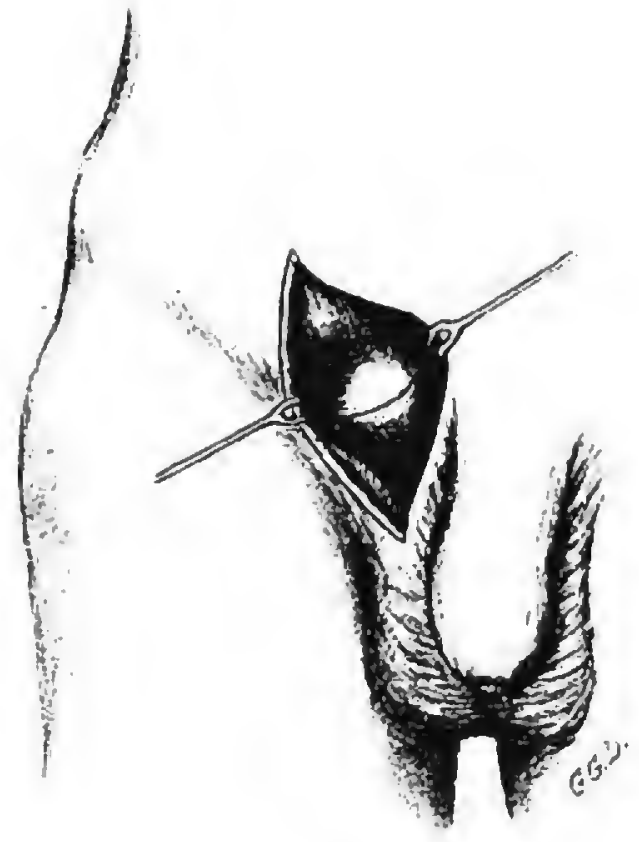

Fis: *. 


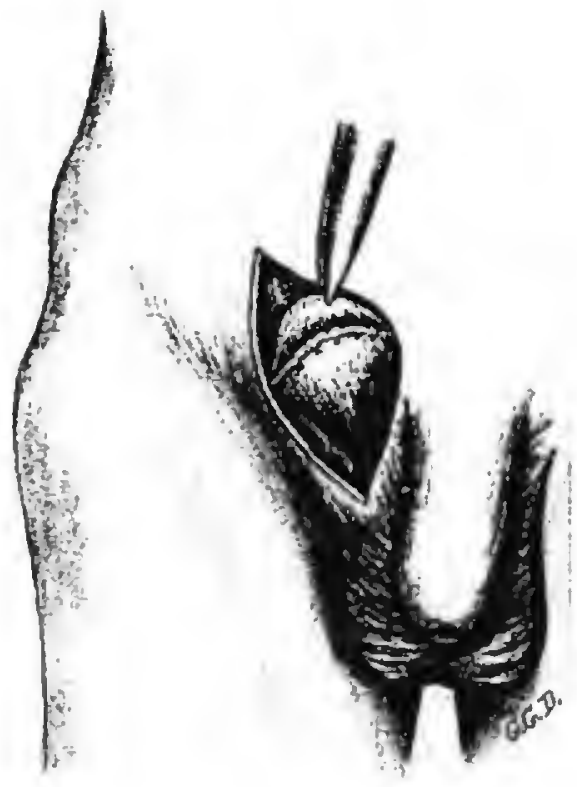

F"s. 

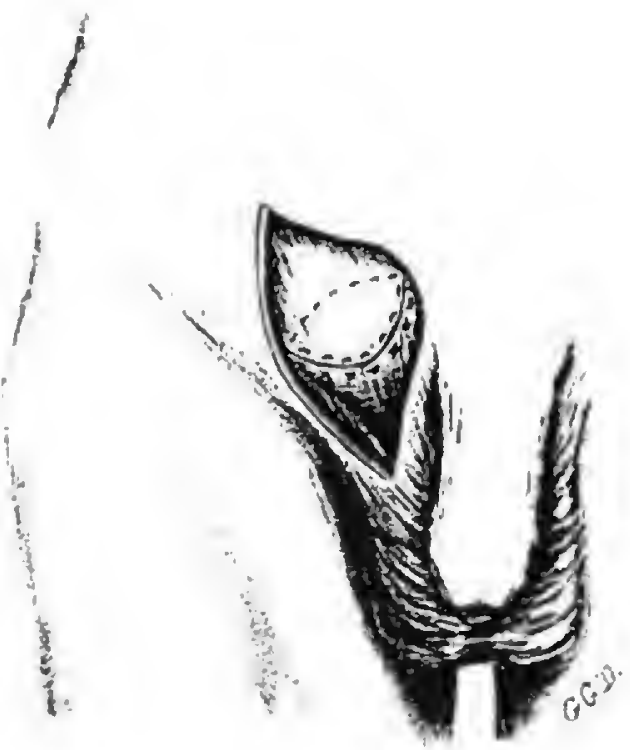

Hiv- 
its anterior surface. Personally I have not been able to draw the rectus as far out as Bloodgood advises.

After having transplanted the rectus as far out as possible then the arching fibres of the internal oblique and conjoined tendon are to be brought down and sutured to Poupart's ligament beneath the cord as in Bassini's operation. The external oblique is then sutured as desired (overlapped or not) over the cord.

In operating on the other form of direct hernia an entirely different state of affairs is presented. The rounded hemispherical tumor presents itself just above the position of the external ring with the cord below. One of two conditions will be found. Especially when the hernia is an old one the hernial coverings from the intestine within to the superficial fascia without will be a single thick strong membrane incapable of being separated into layers. When such a condition is found in several cases I have divided the sac transversely and overlapped its two parts, suturing the apex of the lower flap to the base of the upper and then bringing down the upper flap and suturing it in place as is clone in the Mayos' operation for umbilical hernia. They dissect off the peritoneum but I believe it is better not to do so because it is firmly blended with the other tissues and adds considerable to the strength of the flaps, whereas alone it is too weak to be of much service. (See Figs. 2 and 3.)

In some other cases the peritoneum is not adherent to the conjoined tendon and intercolumnar facsia in front but has a layer of fat between. When such is found, the fat may be scraped away and the two laid together and treated as a single layer and overlapped as already described or some other method may be resorted to. The treatment of these direct hernias is not entirely settled and different methods must be used for different conditions. As the overlapping plan has been found to work satisfactorily in cases of oblique inguinal hernia (Andrews) and umbilical hernia (Mayo) so I believe will it also be found of value in certain cases of direct inguinal hernia. 